\title{
The Rise of Sustainable Fashion - Glossary for an Article
}

\author{
Edit Csanák* \\ Óbuda University, Hungary
}

*Corresponding author: Edit Csanák, Óbuda University, Institute of Product

Design, Budapest, Hungary.

Received Date: October 22, 2018

Published Date: November 15, 2018

\begin{abstract}
The paper "Eco-friendly Concepts and Ethical Movements in the Fashion Industry" seeking to present and to explore the history and application of the eco-friendly and sustainable design concepts in fashion design, has been published as a conference paper, the year 2014 [1,2]. Despite its limitations, its real aim was to introduce the rise of the idea of sustainability in the Fashion World and to draw attention to the core values of the movement. It certainly proved to be a useful source for many authors, given a large number of visitors. This review supplements it with fresh information on the topic and with in-depth examining the concept of sustainable fashion, its goals, and true values attempting to contribute to scientific research for more sustainable fashion.
\end{abstract}

Keywords: Sustainability, Sustainable fashion trend, Ethical fashion, Pillars of sustainability

\section{Introduction}

Fashion faced a nasty reputation these days [3]. Those who work in fashion, love it and do not want clothes to exploit people or destroy the planet. Fashion provides dignified work, not abusing, overworking, harassing, and exploiting or discriminating anyone. Thus, advanced thinkers demand radical change seeking different ways to draw attention to the fact that something went wrong and has to change. They started making over thirty years ago, still: everything seems to be not changed much. The responsibility of the brands and designers is unquestionable in this matter.

Respected trend forecaster and fashion theorist, Li Edelkoort, gave a provocative talk on the stage, sharing her opinions on why the fashion system is destroyed, and how the industry cannot catch up to today's reality regaining its true value. I felt it was dishonest to continue as if everything was still the same." (The Business of Fashion, 2017) Icon, Rei Kawakubo of Comme des Garçons, withdrew "from fashion by her manifest 'Not Making Clothes' year 2017 [4].

Recovering the structure of the Fashion Industry became a crucial issue of the global economy. One of the objectives is sustaining the development by slowing down the processes on the normal rate (Slow Fashion). Naturally, this is just one of the goals. Making a sustainable fashion industry is affected by several factors: protecting the environment, dealing with the recycling and waste, encouraging the development of environmentally friendly materials, fight for fair trade and decent working conditions, support of the traditional skills and protection of the heritage, supply chain management, enforcement of the application of animal-welfare directives are some more. Are these noble goals designed to reduce the environmental footprint of the fashion industry to be compatible with the interests of the Fashion Industry? Can they ever be applied consequently? Can this phenomenon of hectic nature, driven by the eternal transformation, be tamed and compelled? Can fashion ever be sustainable? This study discusses these questions.

\section{Analysis of the Concept- Sustainable Fashion: A Conceptual Disorder?}

Under the concept of sustainable fashion, we consider the processes where the fashion products are created and produced with social responsibility, in respect of the environmental and social impact of the garment. As part of the overall trend, the main aim is to reduce the carbon footprint of the fashion industry, known as the second dirtiest in the world, next to the oil Industry [5].

If analyzed in depth, the often-used concept "sustainable fashion" seems to be a conceptual disorder. Fashion is considered as a temporarily dominant direction of custom style, otherwise: a popular or the latest style of clothing, hair, decoration, or behavior, a manner of doing something. Only appearances that spread massively can come in fashion. Slow and sustainable operation have not ever been the interest of fashion as being contrary to the 
phenomenon which is fundamentally operating in a significant number of occurrences of a new style, and their fast spread. Contribution to a better understanding of the mechanism of fashion and the spread of the new styles is Figure 1.

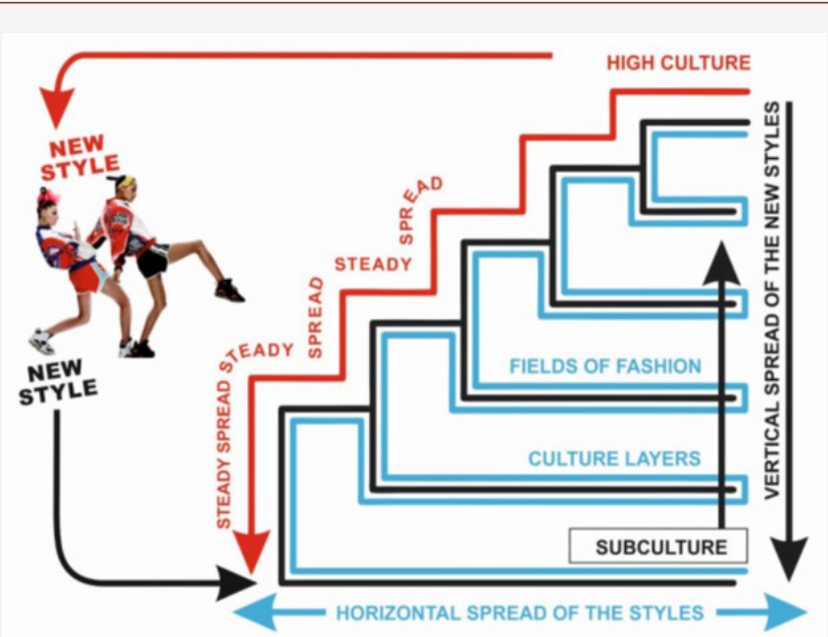

Figure 1: The mechanism of fashion analyzed according to the spread of the new styles

Fashion is a premier cultural factor which mechanism works according to the rules of the cultural phenomena. Culture, as the continuously evolving dynamic interaction of mindsets and gutsets of actors in the system(s), has many points of attachment to sustainability (cultural sustainability). For fashion, that means that the cultural commitment of the designers and brands to sustainability is to create volumes with consideration of their responsibility for sustaining or continuing one's tradition, heritage, craftsmanship, method, and identity as a part of this value. These issues are humanistic endeavors, which unfortunately have nothing to do with Fashion, as a phenomenon.

Sustainable Fashion fights for goals which are to be challenging to pacify with the mechanism of the phenomenon continuously seeking change and new style. Slow Fashion is one of the solutions, yet again completely different to the interest of the global Fashion Industry. Analyses prove that the production of fashion goods is continuously growing [6,7]. Moreover, to keep up, nowadays companies are inventing advanced solutions in order to manage their result-oriented PLMs successfully. To hope that industry representatives can be forced to curb their interests willing to cut their profit also cannot be considered as an objective. Thus: What is Sustainable Fashion about for over thirty years? Is it a longlasting movement? An approach? A humanistic endeavor? A kind of attitude? Or simply: a manner, a pose.

\section{Goals of sustainable fashion}

Saving a planet and eco-awareness are issues prompting every decent human on solidarity and action; something that many people are passionate about and believe in. However, an essential objective of the movement is to support the catching up of the stakeholders with environmentalism and social responsibility; it attempts to achieve complex objectives. These are:

a. Protecting the Environment including Energy and Water
Efficiency Management [8];

b. Recycling and Waste Management for the reuse of the products at the end of their life cycle;

c. Use of Environmentally Friendly Materials for widespread of the organic materials;

d. Fair Trade means a trading partnership based on dialogue, transparency, and respect;

e. Decent Working Conditions ensure the circumstances of the legal work and its standards;

f. Support of Traditional Skills is about the promotion and support of the cultural heritage;

g. Supply Chain Management maintenances the investors to make good choices;

h. Animal-Friendly Policies focus on ethical production and use of animal-derived materials.

\section{The rise of the sustainable fashion movement}

Regarding the evolution of sustainability, it is important to highlight the radical change of the market, around 2007 [9], when Fashion faced a new phenomenon: Fast Fashion. Its greatest support was the growing e-commerce. Ones might guess, but no way to predict, how tremendous impact these will have. The first complex writing analyzing the new channel of the market in the aspect of sustainability has been published a year before in contribution of few authors [10,11].

Table 1: Sustainable Fashion actors with the year and location of the establishment.

\begin{tabular}{|c|c|c|}
\hline Year & Organization & Location \\
\hline 1987 & $\begin{array}{c}\text { EPEA (Environmental Protection } \\
\text { Encouragement Agency) }\end{array}$ & Deutschland \\
\hline 1989 & Clean Clothing Campaign & Bangladesh \\
\hline 1995 & Verite & France \\
\hline 1996 & Textile Environment Design (TED) & United Kingdom \\
\hline 1998 & Ethical Trading Initiative & United Kingdom \\
\hline 2002 & Ethical Trading Organization & United Kingdom \\
\hline 2006 & Ethical Fashion Forum & United Kingdom \\
\hline 2007 & Fashion Takes Action & Canada \\
\hline 2008 & $\begin{array}{c}\text { National Association of } \\
\text { Sustainable Fashion Designers } \\
\text { (SFD) }\end{array}$ & United States \\
\hline 2009 & Eco Age & United Kingdom \\
\hline 2009 & Ethical Trading Initiative & NA \\
\hline 2009 & Sustainable Apparel Coalition & United States \\
\hline 2014 & Fashion Revolution & United Kingdom \\
\hline 2016 & Mistra Future Fashion & Sweden \\
\hline
\end{tabular}

Fast Fashion has accelerated the consolidation of the sustainability trend, increasing the number of movements, associations and their contributors [12]. Table 1 highlights the essential actors of the global Sustainable Fashion Scene. These organizations were consequently disseminating the idea of sustainability organizing online courses, panel discussions, webinars, fashion fairs, and training for start-up fashion brands. 
Still: operation of each organization lays on corporate principles and cost-effectiveness. Each event organized was/is just another form of the fashion business.

\section{The business of sustainable fashion}

The rise of sustainable fashion and the increase of the supporting organizations contributed to the consolidation of flourishing businesses. Ones discovered the potentials and start to make themselves business tagging "sustainability" as a label on their events, services, and products, to make themselves promotion and spectacular hype. Fashion World soon faced that successful application of the objectives does not depend on the enthusiasm of the passionate. The number of so-called sustainable and ethical brands significantly increased, and the market became flooded with products crafted ethically or made in an eco-friendly manner. As the customers cannot trace the supply chain of brands arose accreditation organizations, willing to certify the clarity the brand and the quality of its product.

\section{Sustainable fashion in action}

Referring to an analysis, Millennials think differently about textile sustainability; parenthood affects these attitudes. The survey made the year 2017 monitored the purchase habits of the fashion and textile market consumers, focusing on the Millennials. It claims that 60 percent of them are interested in certified sustainable clothing, and 69 percent check for "environmentally friendly" or "sustainable" label when buying clothes. (Müller, 2018) „Sustainability will be the next major battlefield where brands will compete for millennial spend." (Hahn-Petersen, 2018) Others attempted to examine the relationships between product- and store-related attributes of eco-fashion, and consumption decisions of the fashion consumers, investigating their affiliation to the premium level eco-fashion, known as a less price-sensitive segment of the market [13].

\section{Sustainable fashion education}

Along with the rise of the trend, the number of schools offering custom courses also increased. The education involved the teaching of the young professionals and training of brands - as firstly seemed to be the most important aspect of acting. The first college courses were set around 2008-2010. Quoting Li Edelkoort: "The fashion world is still working in a 20th-century mode celebrating the individual. (It) makes (fashion) old-fashioned." After some years of debate, brands faced that sustainable issues cannot be treated well without fulfillment of the formidable task: the education of the customers to change the consumer habits [14]. The objective to buy less, and choose durable requires a willingness to pay the real cost of the garment. To habituate the customer to learn about the brand (whose products buying) can be successfully realized in medium or high category, and premium products. In the case of mass products, the product history is hardly traceable, although, these products are considered a significant part of the market, proven held responsible for environmental pollution.

\section{The Diagram of Sustainable Fashion}

The three pillars of sustainable development, economic growth, ecological balance, and social progress are in the focus of the analysis. The dynamic of the economic growth and the ecological aspects were in focus of research, while the social pillar has received less attention- until recently. Now a great emphasis has been placed on social issues, however, still not enough [15].

Due to the radical change of the consumption channels, and altered habits, the three-pillar diagram of sustainability in fashion, introduced in the referenced article [16], has to be completed with a new element: the consumer habits. As the fourth pillar of sustainability - the fourth bubble of the diagram - they make the pillars stabile. Even considering them as part of the economic and social conditions, in interaction with the environmental aspects, they have an influence on the ecological balance, and should be analyzed and measured as a separate unit, as shown in Figure 2.

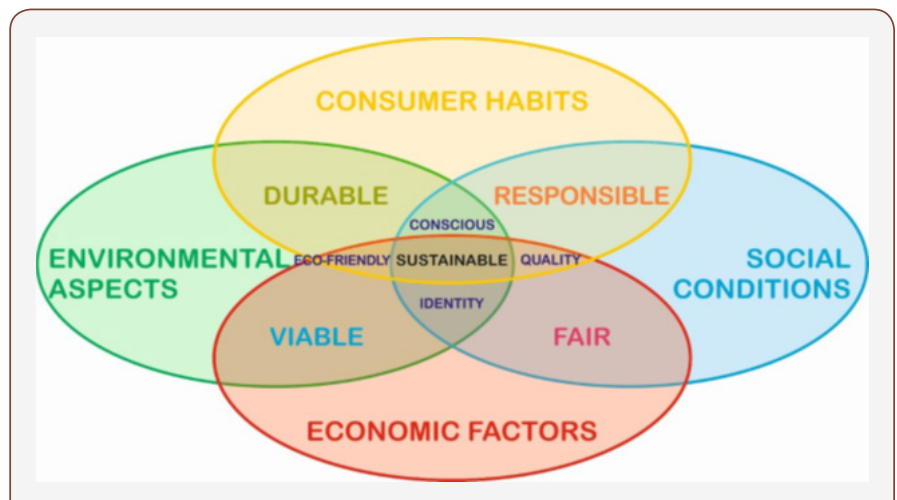

Figure 2: The four-bubble diagram of the sustainable fashion.

The discussion of the specific interactions within the diagram is a topic for further comprehensive research and will be explored after the examination.

\section{Discussion and Summary of the Main Findings}

Sustainable fashion, as a global movement mobilizing large forces of the industry, is idea integrated into the production process of fashion goods; an elementary standpoint which cannot be ignored when designing or manufacturing a collection. After over three decades of its evolution, plenty of organizations, events and platforms, consulting companies, experts and accreditation associations are still trying to apply different solutions in its achieving. As a result of the multiple interpretations, there is still not present a unified methodology which can be applied globally.

Sustainable fashion in part became a form of business, giving work to the arisen number of intellectuals, which are 'attempting to make a visible change actually' while rotating the wheel of the same apparatus. Some recent sources trying to sum the players, initiatives, apparatuses, standard systems, and strategies are highlighting the lack of transparency and control of the complex supply chain, finding it essential management and governance challenges of the future fashion business [17].

Sustainable fashion should not be a trademark selling better the good, nor a goal leading one to look for their benefit. The successful application of the objective's rests in a big deal on the decision of the consumer: if strongly opposed to the consumption of non-quality goods, and willing to pay the real cost of the product, fashion will start to realize the sustainable goals by itself. When 
eco-consciousness, quality-oriented and eco-friendly attitudes perform as a mass trend, the spread of the sustainability will fulfill as a consequence of the new mindset. Until other tendencies are feeding the mechanism (Fast Fashion, mass market), it remains a long-term fight to win the battle.

\section{Acknowledgement}

None.

\section{Conflict of Interest}

No Conflict of Interest.

\section{References}

1. Gwilt A (2014) A practical guide to sustainable fashion. ( $1^{\text {st }}$ edn), Fairchild books, Newyork, USA p.176.

2. Chang TY, Wong CW (2012) The consumption side of sustainable fashion supply chain: Understanding fashion consumer eco-fashion consumption decision. J Fashion Marketing and Management: 16(2): 193-215.

3. Boyd C (2001) Sustainability is good business. Organization for economic cooperation and development. The OECD Observer. 228(3): 35-37.

4. The business of fashion and McKinsey \& company. The State of Fashion 2017.

5. Sweeny G (2018) Fast fashion is the second dirtiest industry in the world, next to big oil.

6. The business of fashion. Anti-fashion: A manifesto for the next decade. Voices: Li Edelkoort.
7. Woo K (2012) Remembering one of Rei Kawakubo's most boundarybreaking shows.

8. Csanák E (2014) Eco friendly concepts and ethical movements in the fashion industry. In: Zvonko, Dragcevic. Proceedings of the $7^{\text {th }}$ International Textile, Clothing \& Design Conference: 553-558.

9. Hoffman L (2007) Future fashion white papers. Earth pledge series on sustainable development. Earth Pledge, Newyork, USA, p.287.

10. Ashworth CJ, Schmidt RÄ, Pioch EA, Hallsworth A (2006) An approach to sustainable 'fashion' e-retail: A five-stage evolutionary strategy for 'Clicks-and-Mortar' and 'Pure-Play' enterprises. J Retailing and Consumer Services 13(4): 289-299.

11. United Nations Environment Programme (UNEP) (2013) Global chemicals outlook: Towards sound management of chemicals.

12. Müller $\mathrm{H}$. The key to confidence: millennials, parents, and textile sustainability.

13. Schneider AM, Jastram S (2018) Sustainable fashion. Governance and new management approaches. Springer International Publishing, USA, pp. 3-8.

14. Sullivan R (2014) Stream of Conscience.

15. Stigson B (2000) Sustainable development, and business. OECD Observer: 221/222.

16. The business of fashion \& McKinsey \& company. The State of Fashion 2018.

17. Hahn-Petersen LA (2018) Millennials say they care about sustainability. So, why don't they shop this way? 